\title{
Educação em saúde nas escolas: conhecimentos de adolescentes sobre o Vírus da
}

\section{Imunodeficiência Humana}

\author{
Health education in schools: knowledge of adolescents about the Human Immunodeficiency Virus \\ Educación para la salud en las escuelas: conocimiento de los adolescentes sobre el Virus de la \\ Inmunodeficiencia Humana
}

Recebido: 07/03/2021 | Revisado: 14/03/2021 | Aceito: 18/03/2021 | Publicado: 23/03/2021

\author{
Amanda Regina da Silva Góis \\ ORCID: https://orcid.org/0000-0003-4661-772X \\ Universidade de Pernambuco, Brasil \\ E-mail: amanda.gois@upe.br \\ Paulo Filipe Cândido Barbosa \\ ORCID: https://orcid.org/0000-0003-0608-1123 \\ Universidade Federal de Pernambuco, Brasil \\ E-mail: pfcb@cin.ufpe.br \\ Vitória Hadassa Gomes Barbosa Gonçalves \\ ORCID: https://orcid.org/0000-0002-3452-0501 \\ Universidade de Pernambuco, Brasil \\ E-mail: vitoriahadassa@hotmail.com \\ Vivian Ferreira da Silva \\ ORCID: https://orcid.org/0000-0001-6816-769X \\ Universidade de Pernambuco, Brasil \\ vivian.ferreiraenf@gmail.com \\ Camila Gabriela da Silva Góis \\ ORCID: https://orcid.org/0000-0002-5106-8705 \\ Universidade Federal de Pernambuco, Brasil \\ gcamilag@gmail.com \\ Regina Célia de Oliveira \\ ORCID: https://orcid.org/0000-0002-6559-5872 \\ Universidade de Pernambuco, Brasil \\ regina.oliveira@upe.br \\ Fátima Maria da Silva Abrão \\ ORCID: https://orcid.org/0000-0003-3254-2851 \\ Universidade de Pernambuco, Brasil \\ Fatima.abrao@upe.br
}

\begin{abstract}
Resumo
Objetivo: apreender os conhecimentos de adolescentes sobre o Vírus da Imunodeficiência Humana e descrever ações de educação em saúde nas escolas. Metodologia: estudo descritivo-exploratório de abordagem mista desenvolvido com aporte teórico da pesquisa-ação, em duas escolas da rede pública, situadas na cidade do Recife, Pernambuco, Brasil. Participaram 188 estudantes do ensino fundamental II e ensino médio. Os dados foram coletados por meio de um questionário com perguntas abertas e fechadas. Para análise dos dados realizou-se estatística descritiva e análise de conteúdo categorial. Resultados: os conteúdos foram organizados em duas categorias: conhecimentos sobre a transmissão e conhecimentos sobre a prevenção. Apreendeu-se que os estudantes reconhecem a atividade sexual desprotegida como principal forma de transmissão do vírus. Mas que não efetivam práticas de prevenção sobre as quais têm conhecimentos superficiais. Entre as ações educativas nas escolas, destacou-se a reflexão sobre a estratégia de prevenção combinada para a transformação das realidades, construção de novos conhecimentos e consolidação dos conhecimentos prévios. Conclusão: considera-se necessário inserir no contexto escolar, de maneira permanente e participativa, a promoção e educação em saúde voltada à transformação e emancipação dos conhecimentos sobre o vírus.
\end{abstract}

Palavras-chave: HIV; Estudantes; Conhecimentos; Educação em saúde; Promoção da saúde.

\begin{abstract}
Objective: to learn the knowledge of adolescents about the Human Immunodeficiency Virus and describe health education actions in schools. Methodology: a descriptive-exploratory study with a mixed approach developed with theoretical support from action research, in two public schools, located in the city of Recife, Pernambuco, Brazil. 188 students from elementary school II and high school participated. Data were collected through a questionnaire with open and closed questions. For data analysis, descriptive statistics and categorical content analysis were performed.
\end{abstract}


Results: the contents were organized into two categories: knowledge about transmission and knowledge about prevention. It was apprehended that students recognize unprotected sexual activity as the main form of transmission of the virus. But they do not carry out preventive practices about which they have superficial knowledge. Among the educational actions in schools, the reflection on the combined prevention strategy for the transformation of realities, the construction of new knowledge and the consolidation of previous knowledge stood out. Conclusion: it is considered necessary to insert in the school context, in a permanent and participatory manner, health promotion and education aimed at the transformation and emancipation of knowledge about the virus.

Keywords: HIV; Students; Health education; Health promotion.

\section{Resumen}

Objetivo: conocer los conocimientos de los adolescentes sobre el Virus de la Inmunodeficiencia Humana y describir las acciones de educación para la salud en las escuelas. Metodología: estudio descriptivo-exploratorio con enfoque mixto desarrollado con apoyo teórico de la investigación acción, en dos escuelas públicas, ubicadas en la ciudad de Recife, Pernambuco, Brasil. Participaron 188 alumnos de primaria II y bachillerato. Los datos fueron recolectados a través de un cuestionario con preguntas abiertas y cerradas. Para el análisis de datos se realizó estadística descriptiva y análisis de contenido categórico. Resultados: los contenidos se organizaron en dos categorías: conocimientos sobre transmisión y conocimientos sobre prevención. Se aprehendió que los estudiantes reconozcan la actividad sexual sin protección como la principal forma de transmisión del virus. Pero no realizan prácticas preventivas de las que tienen un conocimiento superficial. Entre las acciones educativas en las escuelas destacó la reflexión sobre la estrategia combinada de prevención para la transformación de realidades, la construcción de nuevos conocimientos y la consolidación de conocimientos previos. Conclusión: se considera necesario insertar en el contexto escolar, de manera permanente y participativa, la promoción de la salud y la educación orientada a la transformación y emancipación del conocimiento sobre el virus.

Palabras clave: VIH; Estudiantes; Conocimiento; Educación en salud; Promoción de la salud.

\section{Introdução}

O reconhecimento da adolescência é um fenômeno contemporâneo. Estima-se que há no mundo número recorde de adolescentes e jovens, cerca de 1,8 bilhão (UNAIDS, 2019). A adolescência envolve tanto questões físicas e emocionais quanto sociais e políticas que são modificadas de país a país, a depender da cultura e dos aspectos econômicos (Senna \& Dessen, 2015).

Quanto aos limites cronológicos, este período da vida que marca a transição entre a infância e a vida adulta, pode ser definido de maneiras diferentes. Deste modo, a Organização Mundial da Saúde (OMS) define como adolescentes pessoas entre 10 e 19 anos. Enquanto a Organização das Nações Unidas (ONU) entre 15 e 24 anos. Mesmo no Brasil há divergências sobre este período, para o Ministério de Saúde (MS) os limites da faixa etária compreendem pessoas dos 10 aos 24 anos, enquanto o Estatuto da Criança e do Adolescente (ECA), Lei 8.069, de 1990, define a adolescência como a faixa etária de 12 a 18 anos de idade (OPAS, 2015; Brasil, 1990).

Contudo, independente destas variações, consolida-se que a adolescência não é igual para todas as pessoas, mas é definida por profundas transformações no âmbito biopsicossocial. É nesta fase que o ser humano inicia as experiências sexuais, para as quais nem sempre foi devidamente preparado, o que aumenta os riscos e vulnerabilidades que envolvem da gravidez indesejada às Infecções Sexualmente Transmissíveis (IST) (Cardona-Cardona et al., 2017).

Sobre IST, destaca-se a infecção pelo Vírus da Imunodeficiência Humana (HIV) como a mais importante para a saúde pública. Entre adolescentes, o HIV está associado ao baixo nível de conhecimentos sobre as formas de transmissão; percepção de que não são susceptíveis; e uso de substâncias psicoativas como drogas licitas e ilícitas, combinados ao não uso do preservativo e ao acesso limitado a serviços de saúde que compreendam necessidades individuais e subjetivas dos adolescentes (Cardona-Cardona et al., 2017).

No Brasil, desde o início da epidemia do HIV, a maior concentração dos casos da Síndrome da Imunodeficiência Adquirida (SIDA) afeta indivíduos com idades entre 25 e 39 anos (Brasil, 2017). No entanto, os estudos alertam que possivelmente a infecção pelo vírus ocorreu ainda na adolescência (Chaves et al., 2014). Neste sentido, houve um incremento na taxa de detecção entre homens de 15 a 19 anos, sendo a principal via de transmissão em 2018 a sexual, tanto entre homens 
(78,9\%) quanto mulheres (86,9\%) com 13 anos de idade ou mais (Brasil, 2017; Grangeiro, 2016).

Esta não é uma realidade apenas brasileira, no contexto mundial a Organização das Nações Unidas para a Educação, Ciência e Cultura (UNESCO) revela que os adolescentes e jovens entre 15 e 24 anos representam uma população altamente vulnerável e com alto risco de apresentar infecção pelo HIV. O que suscita desafios às formas de superar esta vulnerabilidade e alto risco entre os adolescentes, e para tanto, a Organização Pan-Americana da Saúde (OPAS) destaca que se deve promover conhecimentos a respeito da transmissão do HIV e formas de prevenção. Tendo em vista que a ampliação das informações sobre o tema entre os adolescentes pode influenciar atitudes (Brasil, 2017; Barreto et al., 2019).

Deste modo, a fim de alcançar os adolescentes, a escola surge como cenário ideal, articulando os saberes e conhecimentos à promoção da saúde. No Brasil, nesta perspectiva, inaugurou-se a parceria entre a saúde e educação com o Programa Saúde na Escola (PSE) que aborda os componentes da promoção da saúde sexual e reprodutiva e prevenção de doenças (OPAS, 2017).

No entanto, entraves políticos e marcos ideológicos conservadores têm impedido o avanço destas discussões da educação para a saúde reprodutiva e prevenção de IST no território escolar (Correa, 2018). Mesmo com dados da literatura científica que apontam para a associação entre o adiamento do início da vida sexual à existência de educação sexual nas escolas (Furlanetto, 2018).

O presente estudo objetivou apreender os conhecimentos de adolescentes sobre o Vírus da Imunodeficiência Humana e descrever ações de educação em saúde nas escolas.

\section{Metodologia}

Trata-se de um estudo descritivo-exploratório de abordagem mista desenvolvido com aporte teórico da pesquisa-ação em duas escolas da rede pública, intituladas neste estudo como "Escola A" e "Escola B", situadas na cidade do Recife, Pernambuco, Brasil.

A pesquisa-ação propõe investigar e então transformar a realidade a partir da produção de conhecimento com foco nas necessidades de um determinado grupo microssocial (Thiollent, 2011). E foi desenvolvida em duas fases. A primeira, exploração, relacionada a análise dos conhecimentos de adolescentes sobre o HIV. E, a segunda, ação voltada a descrição das ações de educação em saúde nas escolas.

Como critério de inclusão dos participantes estabeleceu-se tratar-se de estudantes do $8^{\circ}$ e $9^{\circ}$ ano do Ensino Fundamental II ao $3^{\circ}$ ano do Ensino Médio, regularmente matriculados, com idade entre 13 e 18 anos. A coleta de dados foi realizada no turno da manhã no período de agosto a novembro de 2016. E, em março de 2017 foram desenvolvidas as ações educativas e preventivas nas escolas. As ações ocorrem como concebidas nas propostas de atuação participativa pactuadas entre coordenação pedagógica, professores e estudantes das escolas; e os acadêmicos e docentes extensionistas do projeto intitulado: “Abordagem de jovens escolares acerca da Aids”, junto com as Unidades Básicas de Saúde (UBS) que atuam no PSE, no entorno da Universidade de Pernambuco, campus Santo Amaro, aprovado pela Pró-Reitoria de Extensão e Cultura da Universidade de Pernambuco (PROEC - UPE).

A escola A possui 281 estudantes matriculados nos turnos da manhã, tarde e noite, enquanto a escola B 484. No entanto, optou-se por convidar para participar do estudo apenas os alunos da manhã, por adequarem-se aos critérios de inclusão no quesito idade, a partir de 13 anos, já que se constatou que os alunos dos turnos da tarde e noite eram mais velhos, destacando-se que nas turmas da noite todos possuíam mais de 18 anos. Sendo assim, constituiu-se por sorteio uma amostra do tipo aleatória não probabilista composta por 188 estudantes.

Quanto aos instrumentos, elaborou-se para a pesquisa questionário com perguntas abertas e fechadas, objetivando identificar os conhecimentos sobre os fatores de risco/ vulnerabilidade para infecção pelo HIV, apreender o conhecimento 
sobre IST e HIV/AIDS, e possíveis estigmas e preconceitos que interferem na adoção de comportamentos de prevenção, que pudessem nortear ações de educação em saúde.

Após o período de coleta de dados construiu-se um banco de dados através de uma planilha do Microsoft Excel® 2010, na qual foram inseridos os dados para a análise quantitativa, por meio de estatística descritiva. Já os dados qualitativos, oriundo das questões abertas, foram explorados a partir do método de análise de conteúdo, utilizando-se a técnica de análise categorial (Bardin, 2016).

A partir da análise dos dados coletados na primeira etapa do estudo as necessidades dos adolescentes foram consideradas do planejamento à implementação das atividades da segunda fase, as ações de educação em saúde nas escolas. Estas foram elaboradas a fim de consolidar as dimensões participativa, crítica e reflexiva da construção de um novo conhecimento emancipatório. A fase ocorreu sob a supervisão da pesquisadora principal do Grupo de Estudos e Pesquisa em Epistemologia e Fundamentos do Cuidar na Saúde e Enfermagem e a participação de uma mestranda do Programa Associado de Pós-Graduação em Enfermagem da Universidade de Pernambuco (UPE)/ Universidade Estadual da Paraíba (UEPB) e duas acadêmicas do curso de enfermagem da Faculdade de Enfermagem Nossa Senhora das Graças (FENSG), UPE, sendo uma delas bolsista de iniciação científica da Fundação de Amparo à Ciência e Tecnologia do Estado de Pernambuco (FACEPE).

Salienta-se que as coordenações pedagógicas e professores de ambas as escolas se envolveram nas ações educativas, sobretudo como facilitadores de sua implementação e estavam presentes em sala de aula quando ocorreram. Houve agendamento prévio para não comprometer o calendário acadêmico e a previsão do conteúdo foi adequado para dialogar com as atividades propostas nas ações.

Para o desenvolvimento desta pesquisa foram respeitadas as normas e diretrizes para a realização de pesquisas envolvendo seres humanos, Resolução 466/2012. Utilizou-se do parecer do projeto ampliado do qual originou-se esta pesquisa e as ações de extensão. O projeto ampliado denominado: "Representações sociais de estudantes de escolas públicas acerca da Aids" foi apresentado ao Comitê de Ética da Universidade de Pernambuco sob o CAAE 03618912.5.0000.5207, obtendo parecer favorável número 107/12, em 02 de julho de 2013.

Ainda quanto aos aspectos éticos destaca-se o Termo de Consentimento Livre e Esclarecido (TCLE), apresentado aos estudantes e responsáveis, tratando-se de menores de 18 anos, além das autorizações institucionais pertinentes a cada campo de pesquisa.

\section{Resultados}

Do total da amostra obtida, 188 estudantes, 94 estudantes são da Escola A, desses 69 são do ensino médio e 25 são do ensino fundamental II, da Escola B 70 são alunos do ensino médio, enquanto 24 são do ensino fundamental II, $8^{\circ}$ e $9^{\circ}$ anos.

Predominou-se estudantes do sexo feminino em ambas as escolas. Em relação à orientação sexual dos participantes, constatou-se um maior quantitativo de sujeitos declarados heterossexuais com idade entre 16 a 18 anos, correspondendo a 51,60\% da população total, 40, 21\% optaram por não declarar, 5\% declararam-se bissexuais e 3,19\% declarados homossexuais.

Dos alunos, 37,77\%, afirmaram ter relações sexuais (sexualmente ativos), enquanto 61,17\% dos alunos declararam que ainda não tiveram relações sexuais e 1,06\% preferiu não declarar. Dos estudantes sexualmente ativos participantes deste estudo, $15,49 \%$ declararam que não utilizaram método preventivo nas relações sexuais enquanto, $84,51 \%$ dos alunos declaram que utilizaram algum tipo de método para prevenção de IST. Importante ressaltar que mais da metade do quantitativo de alunos pesquisados têm a consciência da necessidade de se proteger usando preservativo enquanto se relacionam sexualmente.

A partir da análise das respostas dos estudantes destacou-se relatos que possibilitaram o emergir de duas categorias: conhecimentos sobre a transmissão e, conhecimentos sobre a prevenção. 


\subsection{Categoria: conhecimentos sobre a transmissão}

A categoria revela que alguns dos estudantes conhecem as principais formas de transmissão do HIV e destacam a transmissão sexual como uma condição relacionada a atividade sexual desprotegida. Situam a doença associada ao vírus e atribuem potencial para causar a baixa na imunidade, deixando o corpo susceptível ao adoecimento, revelando conhecimento sobre o desenvolvimento ou evolução da doença e do agente etiológico, o vírus.

\footnotetext{
"Um tipo de doença que é transmitida pelo sexo oral, vaginal ou anal[...]mas só pega se o parceiro ou parceira estiver com a doença". Estudante 30

"Uma doença sexualmente transmissível que baixa a imunidade das pessoas". Estudante 48

“[...]uma doença...quando contamina o corpo, deixa a imunidade baixa e o corpo desprotegido”. Estudante 56
}

Sobre a transmissão do vírus e o desenvolvimento da doença os estudantes destacaram que informações recebidas e o conhecimento que possuem não são suficientes para preencher as dúvidas e que os mesmos sentem a falta de abordagens diferentes sobre o assunto, visto que uma grande parte ainda persiste com dúvidas sobre o tema.

Alguns adolescentes associam abraços e beijos, ou compartilhamento de objetos como talheres, copos e outros utensílios domésticos como eventos passíveis da transmissão do vírus.

“[...] pode pegar... no beijo também... porque pode ter alguma coisa na boca[...] e do mesmo jeito se beber do mesmo lugar da pessoa ou comer com as mesmas colheres". Estudante 03

“[...]beijo, abraço...e outras coisas assim mais quentes... já pode pegar [...]” Estudante 96

“[...] tem que ter cuidado também onde senta[...] se a pessoa usar sua toalha[...]” Estudante 130

Para refletir criticamente sobre estes aspectos elaborou-se uma ação na qual foram apresentadas situações e os estudantes foram estimulados a compartilhar opiniões e conhecimentos sobre a capacidade destas e outras situações de resultar em infecção pelo HIV.

Neste sentido, as ações de educação em saúde, com o uso das metodologias participativas, integraram aspectos lúdicos à elaboração dos recursos didático-pedagógicos da preferência dos adolescentes, como um jogo de mitos e verdades sobre as vias de transmissão do vírus, para o qual produziu-se cartazes e um álbum seriado. Para outras turmas foi elaborado um jogo de trilha em que os participantes são as peças que devem se locomover pelas casas e superar os desafios propostos.

Outros participantes do estudo trazem o contexto da morte como algo certo e esperado para pessoas vivendo com HIV (PVHIV), independentemente da existência de terapia antirretroviral e prevenção.

\footnotetext{
“...que pode levar à morte com o tempo”. Estudante 163

“...vai se implantando e nos consumindo aos poucos...”. Estudante 36
}

Nesse sentido, sobre o desenvolvimento da doença, há presença do medo da morte relacionada a inexistência de cura ou de irreversibilidade do diagnóstico. E para discutir as implicações da transmissão do HIV e do curso dos primeiros sintomas da infecção ao adoecimento realizou-se uma ação de educação em saúde que integrou conhecimentos de aspectos biológicos 
como conceitos de vírus, saúde-doença, e considerações socioculturais sobre as quais incidem medos e preconceitos, que são reflexos da superficialidade de conhecimentos.

\subsection{Categoria: conhecimentos sobre prevenção}

Embora informados sobre a transmissão, o nível de conhecimento ou informação sobre o HIV/AIDS e outras IST, não garante por si só mudanças de comportamento. Espera-se que ações de promoção e educação em saúde possam corroborar para estas mudanças.

Um fator importante para a prevenção é o reconhecimento das vulnerabilidades e riscos. No trecho a seguir os estudantes destacam vulnerabilidades de grupos específicos e comportamentos.

"as pessoas com maior risco de vulnerabilidade são travestis, mulheres transexuais, homens. São pessoas que trabalham como profissionais do sexo”. Estudante 38

“[...] os moradores de rua e usuários de drogas”. Estudantes 129

“Ainda hoje as pessoas continuam relapsas, principalmente quando estão na balada”. Estudante 09

Destaca-se também que além de indicar como grupos de risco ou vulneráveis, grupos aos quais não considera pertencer alguns alunos relatam a si mesmo e as pessoas de uma forma geral como vulneráveis, fato importante para a prevenção.

“todas as pessoas são vulneráveis a adquirir o HIV quando não usam os preservativos nas relações sexuais”. Estudante 21

“todas as pessoas, todos os seres humanos[...]”. Estudante 100

Neste sentido, os adolescentes participantes desta pesquisa possuem informações sobre a prevenção do HIV. Contudo estas ainda são insuficientes para articular mudanças nos comportamentos, condutas e atitudes, por diversos fatores, tais como a utilização de fontes pouco ou não confiáveis e a restrita acessibilidade ao debate sobre essas informações junto a familiares e professores, o que fragiliza o conhecimento sobre a prevenção e as atitudes de prevenção propriamente ditas.

Alguns dos adolescentes que participaram do estudo referiram em suas respostas ao questionário aberto, utilizado na primeira fase da pesquisa para a coleta de dados, a importância da contribuição da escola e de poderes públicos na prevenção.

"Precisava ter um maior foco nas escolas[...]". Estudante 02

“[...] a prevenção poderia ser feita com mais campanhas do governo”. Estudante 22

Assim associando as informações iniciais sobre o perfil dos estudantes, embora conheçam as formas de prevenção, na prática alguns revelam, não as efetivam. A resposta a seguir destaca esse conhecimento sobre a prevenção.

“...pode ser prevenida com tratamento e uso de preservativos”. Estudante 23

“[...] usando camisinha em todas as relações sexuais, seja ela oral, anal ou vaginal e não compartilhando objetos perfuro cortante”. Estudante 17

Sendo assim, o simples fato de se ter algum conhecimento ou informação não implica necessariamente na adoção de 
medidas preventivas. O presente estudo mostra a necessidade de os estudantes receberem mais orientações sobre, principalmente, o uso do preservativo masculino e feminino, a fim de que no momento da relação sexual a insegurança sobre o uso correto do preservativo não desmotive seu uso ou subestime a importante dele para a prevenção de IST e HIV/AIDS.

As respostas dos adolescentes refletem que o medo tem sido usado como um modelo de repressão não efetivo para a prevenção, pois, reforça preconceitos e revela que os adolescentes desconhecem outras estratégias. Entre as ações educativas realizadas nas escolas, destaca-se a apresentação e discussão da estratégia de prevenção combinada, tendo em vista que os adolescentes revelaram como essencial para a transformação de suas realidades a aproximação dos novos conhecimentos propostos com a prática, e para tanto desejavam ver, tocar e manipular os insumos.

E neste contexto, apresentou-se os recursos e insumos como o teste rápido, preservativo feminino e masculino, os antirretrovirais utilizados na profilaxia pré-exposição (PrEP), para situações específica e a profilaxia pós-exposição (PEP). Na oportunidade referenciou-se os serviços de saúde que oferecem estes recursos gratuitamente nas proximidades das escolas. A ação possibilitou a construção de novos conhecimentos e consolidou conhecimentos prévios sobre o tema. A abordagem participativa propiciou um maior interesse dos adolescentes, que interagiram com questionamentos e reflexões.

\section{Discussão}

Apreender o conhecimento de adolescentes sobre o tema podem contribuir para o reconhecimento das mudanças de atitude que podem ser implementadas por meio da promoção e educação em saúde. Tendo em vista que durante a fase da adolescência, o indivíduo está aberto a novas formas de aprendizagens e conhecimentos, sendo observadas à adesão de condutas que posteriormente, poderão ser utilizadas durante a vida adulta (OPAS, 2017; Monteiro et al., 2019; Brasil, 2017).

$\mathrm{O}$ presente estudo aborda que os conhecimentos sobre o assunto se consolidam em duas bases fundamentais, tratadas na apresentação dos resultados como categorias: conhecimentos sobre a transmissão; e, conhecimentos sobre a prevenção.

Sobre a transmissão, a relação sexual sem preservativo é destacada pelos participantes como principal forma de transmissão. Em uma pesquisa realizada com adolescentes de escola pública em Fortaleza, Ceará, Brasil a maioria dos envolvidos reconheceu a relação sexual com penetração vaginal sem camisinha e o compartilhamento de seringas (Chaves et al., 2014).

Um outro estudo realizado em Recife, Pernambuco, Brasil apontou que adolescentes conhecem as questões que envolvem o HIV/AIDS. No entanto, observa-se que independente no nível de informação e conhecimento sobre a necessidade do uso do preservativo em todas as relações sexuais alguns adolescentes persistem em não usar o preservativo (Angelim et al., 2015). O que para outros autores justifica-se diante de uma crença entre os adolescentes sobre a dispensa do uso de camisinha quando consideram seus parceiros saudáveis e quando neles confiam (Carvalho et al., 2017).

Uma condição antecedente para o conhecimento sobre HIV/AIDS é o acesso aos conteúdos que discutam sobre a sexualidade. Alguns autores em sua investigação constataram que a televisão, internet e os professores foram os principais meios de comunicação pelos quais os estudantes recebem informação sobre o tema (Chaves et al., 2014). Corroborando com os achados desta pesquisa, que apresenta a dificuldade dos adolescentes e jovens em conversar com a família.

Discute-se sobre os dados apresentados que a abordagem da prevenção combinada e o enfoque no uso de preservativo continua sendo necessário. Observa-se que há defasagem entre o conhecimento dos adolescentes e suas atitudes de prevenção. O que compromete a tomada de decisão frente a realidade vivenciada na iniciação de experiências sexuais.

Dialogando com este achado, fomenta-se com grande relevância as iniciativas para uma compreensão da prevenção combinada, esta por sua vez, fundamentada nos direitos humanos. A ampliação do conhecimento e acesso aos métodos preventivos incluem abordagens biomédicas, comportamentais e estruturais, que como demonstrou-se eram superficialmente conhecidas pelos estudantes o que pode comprometer a tomada de decisão sobre as opções de prevenção (Gavigan et al., 
2015).

Fica claro que, para a conscientização dos adolescentes e jovens acerca da prevenção, não é suficiente apenas conhecer os métodos, mas também saber sobre a eficácia, importância, e como ter acesso a eles. Bem como a forma correta de sua utilização e as possíveis consequências do não uso, mesmo em casos de relacionamentos estáveis (Monteiro et al., 2019).

Torna-se necessária a ocorrência de práticas educativas de acordo com a cultura, a visão de mundo e a realidade da faixa etária como demonstram estudos realizados em países como Malasia (Mansor, Ahmad \& Rahman, 2020) e China (Han et al., 2019).

Além disso, é imprescindível estabelecer uma relação de troca com os adolescentes e jovens, deixá-los expor seus conflitos, ouvi-los, trabalhar a autoestima, o relacionamento interpessoal, a imagem corporal e a afetividade. Considerando-se o contexto social e cultural, ampliando o acesso da população jovem de camadas populares aos serviços, insumos e informações em HIV/AIDS. Principalmente em tempos de retrocesso da discussão desses temas no contexto escolar que limitam o acesso ao direto à prevenção e colaboram para a reemergência de desafios antes considerados como superados (Paiva, Antunes \& Sanchez, 2020; Grangeiro, 2016).

Quanto às limitações do estudo, afirma-se que mesmo com as ações educativas efetivadas em uma interlocução com as escolas incluídas houve dificuldade de acesso às outras instituições de educação. Fato que foi atribuído aos avanços de ideologias alusivas ao conservadorismo que limitaram o interesse das escolas para os temas que envolvem tópicos como gênero e sexualidade.

Diante disso, o projeto ampliado que derivou o estudo foi diversas vezes interrompido e a continuidade das atividades de pesquisa-ação nas escolas não foram consolidadas a longo prazo como estava previsto no planejado inicial. O que certamente implicará em prejuízo para as transformações conquistadas, corroborando para retrocessos, tendo em vista que a cada momento novas necessidades sobre o tema surgem e que o ciclo escolar sempre apresenta novos atores, e esses sem a continuidade das ações não serão alcançados.

Como contribuição articulou-se o vínculo ensino-serviço envolvendo-se com as atividades já desenvolvidas pelo PSE das UBS do entorno do campus, e consolidou-se a integração às dimensões pesquisa e extensão entre estudantes da graduação e pós-graduação em enfermagem.

\section{Considerações Finais}

A apreensão dos conhecimentos de adolescentes sobre HIV apontou que nem sempre o conhecimento por si só revela mudança na realidade, mas que a mudança se relaciona ao acesso à informação e conhecimentos. Desta forma considera-se necessário inserir no contexto escolar a promoção e educação em saúde voltada a prevenção, atuando para a transformação do conhecimento e atitudes de adolescentes e jovens com foco em suas reais necessidades. Destaca-se que as ações com abordagens mais participativas com enfoque no acesso aos serviços de saúde e aos insumos preventivos despertou maior interesse entre os adolescentes.

O incentivo a adoção de estratégias de educação em saúde de maneira permanente entre escolas e serviços de saúde, precisa dialogar com as famílias e considerar aspectos ideológicos, importantes para alguns grupos, de maneira à conciliar direitos sociais e escolhas saudáveis na construção de um novo conhecimento emancipatório no contexto de vida e de relacionamentos dos adolescentes escolares.

\section{Referências}

Angelim, R. C. M., Abrão, F. M. S., Cabral, L. R., Queiroz, S. B. A., Freitas, R. M. M., \& Cardoso, M. D. (2015). Conhecimento de estudantes adolescentes acerca do HIV/Aids. Revista de Enfermagem da UFSM, 67(1), 48-53. doi:http://dx.doi.org/10.5902/2179769214869 
Bardin, L. (2016) Análise de conteúdo. São Paulo: Editora 70.

Barreto, M. A. S. A., Suto, C. S. S., Oliveira, J. S. B., Vilas Boas, J.M., Porcino, C., \& Moraes, A.A.S. (2019). Representações sociais de estudantes de ensino médio da rede pública sobre prevenção em HIV/Aids. Cienc Cuid Saúde, 18(4), e45285. doi: https://doi.org/10.4025/cienccuidsaude.v18i4.45285

Brasil. (1990). Lei 8.069, de 13 de julho de 1990. Estatuto da Criança e do Adolescente. Brasília: Ministério da Justiça.

Brasil. Ministério da Saúde. Secretaria de Vigilância em Saúde. Departamento de DST, AIDS e Hepatites Virais. (2017). Boletim epidemiológico: AIDS e IST. Ministério da Saúde, 20, 1-64.

Brasil. Ministério da Saúde. Secretaria de Vigilância em Saúde. Departamento de Vigilância, Prevenção e Controle das Infecções Sexualmente Transmissíveis, do HIV/Aids e das Hepatites Virais. (2017). Prevenção Combinada do HIV/Bases conceituais para profissionais, trabalhadores(as) e gestores(as) de saúde. Brasília (DF): Ministério da Saúde.

Cardona-Cardona, M. I., Posada-Mora, S., Cadavid-Ruiz, N., \& Orcasita, L. T. (2017). Programas de intervenção efetivos para a prevenção do HIV em adolescentes e jovens: uma revisão sistemática. Adolesc. Saúde, 14(4), 167-183.

Carvalho, C. P., Pinheiro, M. R. M., Gouveia, J. P., \& Vilar, D. R. (2017). Conhecimentos sobre sexualidade: Construção e validação de um instrumento de avaliação para adolescentes em contexto escolar. Revista Portuguesa de Educação, 67(1), 48-53. doi: https://dx.doi.org/10.21814/rpe.9032

Chaves, A. C. P., Bezerra, E. O., Pereira, M. L. D., \& Wolfgang, W. (2014). Conhecimentos e atitudes de adolescentes de uma escola pública sobre a transmissão sexual do HIV. Rev bras enferm, 67(1), 48-53. doi: https://doi.org/10.5935/0034-7167.20140006

Chaves, C. S., Rouberte, E. S. C., Costa, E. C., Moura, A. D. A., Rodrigues, V. C., Souza, A. L. S., \& Dantas. (2021). Vulnerability of adolescents to sexually transmitted infections/HIV. Brazilian Journal of Health Review, 4(2), 4880-4898. doi:10.34119/bjhrv4n2-072

Correa, S. (2018). A política de gênero: um comentário genealógico. Cad Pagu, 53(1), e185301. doi: http://dx.doi.org/10.1590/18094449201800530001

Furlanetto, M. F., Lauermann, F., Costa, C. B., \& Marin, A. H. (2018). Educação sexual em escolas brasileiras: revisão sistemática da literatura. Cadernos de Pesquisa, 48(168), 550-571. doi: https://dx.doi.org/10.1590/198053145084

Grangeiro, A. (2016). Da estabilização à reemergência: os desafios para o enfrentamento da epidemia de HIV/Aids no Brasil. In: Basthi, A., Parker, R., \& Terto-Júnior, V. Mito vs realidade: sobre a resposta brasileira à epidemia de HIV e Aids em 2016. Rio de Janeiro: ABIA, Observatótio de Políticas de Aids. p. $18-23$.

Han, J., Li, J., Wang, K. R., Jiang, T. J., Song, B., Wang, H. et al. (2020). Status and influencing factors of knowledge awareness and service acceptance of HIV non-occupational post-exposure prophylaxis of men who have sex with men among college students among three cities of China, 2019. Chinese journal of preventive medicine, 54(11), 1220-1226. doi: 10.3760/cma.j.cn112150-20200310-00302

Kirby, D., Obasi, A., \& Larisa, B.A. (2006). The effectiveness of sex education and HIV education interventions in schools in developing countries. World Health Organ Tech Rep Ser, 938(1),103-50.

Mansor, N., Ahmad, N., \& Rahman, H. A. (2020). Determinants of knowledge on sexually transmitted infections among students in public higher education institutions in Melaka state, Malaysia. PLoS One, 15(10), e0240842. doi: https://doi.org/10.1371/journal.pone.0240842

Monteiro, R. S. M., Feijão, A. R., Barreto, V. P., Silva, B. C. O., Neco, K. K. S., \& Guimarães, A. A. R. (2019). Ações educativas sobre prevenção de HIV/AIDS entre adolescentes em escolas. Enfermería Actual de Costa Rica, 37(1), 206-222. doi: http://dx.doi.org/10.15517/revenf.v0ino.37.36749

Organização Pan-Americana da Saúde. Ministério da Saúde. (2017) Saúde e sexualidade de adolescentes. Construindo equidade no SUS. Brasília: OPAS, MS.

Organização Pan-Americana da Saúde. Ministério da Saúde. Saúde e sexualidade de adolescentes. Construindo equidade no SUS. Brasília: OPAS, MS.

Paiva, V., Antunes, M. C., \& Sanchez, M. N. (2019). O direito à prevenção da Aids em tempos de retrocesso: religiosidade e sexualidade na escola. Interface Comunicação, Saúde, Educação, 24(1), e180625. doi: https://doi.org/10.1590/Interface.180625

Senna, S. R. C. M., \$ Dessen, M. A. (2015). Reflexões sobre a saúde do adolescente brasileiro. Psic. Saúde \& Doenças, 16(2), 217-229. doi: http://dx.doi.org/10.15309/15psd160208.

Thiollent, M. (2011) Metodologia da pesquisa-ação. 18th ed. São Paulo: Cortez.

UNAIDS. (2019). Transformando as Nações Unidas em um espaço mais inclusivo para os jovens. 2019. 